\title{
Propionato de Cálcio no Amaciamento do Músculo Longissimus dorsi de Bovinos de Corte
}

\author{
Aparecida Carla de Moura Silveira Pedreira1, Paulo Roberto Leme ${ }^{2^{*}}$, Angélica Simone Cravo \\ Pereira $^{3}$, Albino Luchiari Filho ${ }^{2}$
}

\begin{abstract}
RESUMO - A maciez da carne é influenciada pela atuação do sistema proteolítico das calpaínas, durante o processo de maturação pósmorte. O propionato de cálcio fornece cálcio suficiente para aumentar a concentração de cálcio plasmático e, assim, ativar essas proteases dependentes de cálcio, melhorando a maciez da carne. Os objetivos desta pesquisa foram avaliar o efeito do fornecimento via oral de propionato de cálcio nas características quali-quantitativas da carcaça de bovinos de corte. Neste estudo, 24 machos castrados (3/4 Simental+1/4 Nelore) receberam, por via oral, os tratamentos 0 ou $630 \mathrm{~g}$ de propionato de cálcio, 12 horas antes do abate. Após o abate, foram estudados o amaciamento e as perdas por cozimento após 1, 8 e 15 dias de maturação, a análise sensorial, o pH da carne, a área do olho do lombo, a espessura de gordura, os rendimentos da carcaça e a concentração de cálcio no plasma e no músculo Longissimus dorsi. Os resultados mostraram que o tratamento com propionato de cálcio não teve efeito sobre as características de carcaça, a concentração de cálcio no músculo Longissimus dorsi, a força de cisalhamento, as perdas por cozimento e a maciez, o sabor e avaliação geral na análise sensorial. O tratamento com propionato de cálcio aumentou a concentração de cálcio plasmático e melhorou a suculência sensorial.
\end{abstract}

Palavras-chave: contra-filé, gado de corte, maciez da carne, propionato de cálcio

\section{Longissimus dorsi Muscle Tenderness from Beef Cattle Treated with Calcium Propionate}

\begin{abstract}
Beef tenderness is influenced by the activity of the calpain proteolytic system during postmortem aging. Calcium propionate increases blood calcium concentration enough to active these calcium-dependent proteases, and improve beef tenderness The objectives were to evaluate calcium propionate orally supply in quali-quantitative carcass characteristics of beef cattle. In this study, 24 steers ( $3 / 4$ Simenthal $+1 / 4$ Nellore) received 0 or $630 \mathrm{~g}$ calcium propionate orally, 12 hours before slaughter. After slaughter, tenderness (shear force), cooking losses (1,8 and 15 days of aging time), sensory evaluation, muscle pH, Longissimus muscle area, fat thickness, carcass yield grade, blood plasma and muscular calcium determination from Longissimus dorsi muscle were evaluated. The results showed that calcium propionate treatment did not affect carcass characteristics, Longissimus dorsi muscle calcium concentration, shear force, cooking losses, and tenderness, flavor and overall sensory analysis. Calcium propionate increased calcium plasmatic concentration and improved sensorial juiciness.
\end{abstract}

Key Words: beef cattle, calcium propionate, Longissimus dorsi, meat tenderness

\section{Introdução}

O sistema proteolítico das calpaínas é constituído das proteases m- e m-calpaína, e o inibidor calpastatina. Após o abate, essas proteases são ativadas devido ao aumento da concentração de cálcio muscular, melhorando a maciez da carne. Na carne, a concentração de cálcio é relativamente baixa, o que limita a atividade dessas proteases (Goll, 1991). O aumento na concentração de cálcio, por via exógena (injeção ou infusão de $\mathrm{CaCl}_{2}$ e/ou fornecimento de vitamina $\mathrm{D}_{3}$ ) faz com que o processo de maturação seja acelerado, reduzindo, então, o tempo de maturação pós-morte e melhorando a maciez da carne (Moura et al., 1996; 1999; Swanek et al., 1999; Scanga et al., 2001).

O propionato de cálcio é utilizado em vacas com problemas de febre do leite (hipocalcemia aguda), aumentando os níveis de cálcio sangüíneo. Desse modo, como as protases dependentes de cálcio dependem de níveis elevados de cálcio circulante para serem ativadas, o propionato de cálcio também pode ser utilizado para melhorar a maciez da carne.

Em trabalhos de Duckett et al. (1998, 1999b, 2000, 2001), bovinos tratados com propionato de

\footnotetext{
1 Doutoranda, Departamento de Zootecnia, USP/ESALQ, Piracicaba, Bolsista FAPESP. E.mail: acmspedreira@yahoo.com.br

2 Professor Doutor, Departamento de Zootecnia - USP/FZEA, Pirassununga.

3 Doutoranda, Departamento de Zootecnia, USP/FZEA, Pirassununga, Bolsista FAPESP.

* Autor correspondente: prleme@usp.br
} 
cálcio apresentaram um aumento na concentração de cálcio plasmático, aumento de cálcio total no músculo Longissimus, maior atividade de $\mu$ - e m-calpaína e redução dos valores de WarnerBraztler shear force (melhorou a maciez), o que resultou em rápida taxa de amaciamento pós-morte e aumento da maciez em menores tempos de maturação, mas não foram encontradas diferenças entre os tratamentos, para as características quantitativas da carcaça. Os mesmos resultados para a maciez do músculo Longissimus também foram encontrados por Hanson et al. (2001).

Em cordeiros Callipyge, Duckett et al. (1999a) realizaram um trabalho em que se utilizaram tratamentos com diferenças na aplicação de gel de cálcio e nos tipos de processos de maturação. Neste experimento, a administração do gel de cálcio antes do abate aumentou a concentração de cálcio sérico, ionizado e normalizado. Entretanto, o amaciamento da carne não foi um sucesso, mas o congelamento antes da maturação acelerou a taxa de maturação e reduziu os valores de Warner-Braztler shear force a níveis aceitáveis.

Dessa maneira, os objetivos deste trabalho foram avaliar o efeito do fornecimento via oral de propionato de cálcio (12 horas antes do abate dos animais), nas características quali-quantitativas da carcaça de animais 3/4Simental $+1 / 4$ Nelore.

\section{Material e Métodos}

Foram utilizados 24 animais machos, castrados 3/4Simental $+1 / 4$ Nelore, provenientes do rebanho de confinamento da Faculdade de Zootecnina e Engenharia de Alimentos (FZEA), da USP, em Pirassununga-SP.

Este animais permaneceram em confinamento por um período de 120 dias, antes do fornecimento do tratamento com propionato de cálcio, recebendo uma ração contendo (\% da MS): uréia $(0,3 \%)$, farelo de soja $45 \%(5 \%)$, cloreto de potássio $(0,4 \%)$, sal mine$\operatorname{ral}(0,6 \%)$, silagem de milho $(32,5 \%)$, milho grão seco $(27,5 \%)$, bagaço cana in natura $(10 \%)$, polpa citrus peletizada $(15 \%)$, soja extrusada $(8,7 \%)$ e rumensina $(0,03 \%)$. Aos animais foram fornecidos tratamentos com $0 \mathrm{~g}$ ou $630 \mathrm{~g}$ de propionato de cálcio (Fungibal ${ }^{\circledR}$ ), 12 horas antes do abate dos animais. $\mathrm{O}$ fornecimento foi feito por via oral, misturando os $630 \mathrm{~g}$ de propionato de cálcio em 2 L de água.

Antes do abate, os animais foram pesados para registro do peso vivo (PV). Após o abate, a carcaça foi pesada quente (PCQ), GRPI (gordura renal- pélvica-inguinal) e tomadas as temperatura (T0) e pH ( $\mathrm{pH} 0$ ) às 0 horas; em seguida as $1 / 2$ carcaças foram resfriadas por um período de $24 \mathrm{hs}$ em câmara fria $\left(4^{\circ} \mathrm{C}\right)$. Vinte e quatro horas após o abate, as carcaças foram pesadas para obtenção do peso da carcaça resfriada (PCR), traseiro especial (TE), dianteiro com 5 costelas, (D5C), ponta de agulha (PA), e a temperatura (T24) e o $\mathrm{pH}$ (pH24) foram determinados. A área do olho de lombo (AOL) foi medida entre a $12^{\mathrm{a}}$ e $13^{\mathrm{a}}$ costela, no lado esquerdo da carcaça, utilizando um "grid" de plástico (padrão USDA) quadriculado com 10 quadrados por cada $6,4516 \mathrm{~cm}^{2}$. A espessura da gordura (EG) foi medida entre a $12^{\mathrm{a}}$ e $13^{\mathrm{a}}$ costela, no lado esquerdo da carcaça, com uma régua graduada específica para a medição da gordura. Foram ainda estimadas as porcentagens de carcaça quente (RQ), da carcaça resfriada (RF), do traseiro especial (PTE), do dianteiro com 5 costelas (PD), da ponta de agulha (PPA), da área do olho do lombo (AOL/100 kg carcaça resfriada), espessura de gordura (EG/100 kg carcaça resfriada) e PGRPI (porcentagem gordura renal-pélvica-inguinal). De cada animal abatido foram retiradas porções entre a $12^{\mathrm{a}}$ costela e a $5^{\mathrm{a}}$ vértebra lombar, que serviram para a avaliação da maciez e testes de cozimento, obtendose valores da força de cisalhamento (WBSF), porcentagem de perdas por evaporação (PPE), perdas por gotejamento (PPG) e perdas totais (PPT). Além disso, uma porção de carne, na mesma localização, foi utilizada para determinação da concentração de cálcio $\left(\mathrm{CA}_{\mathrm{m}}\right)$ e análise sensorial (AS).

Os procedimentos para a análise da WBSF e perdas por cozimento seguiram recomendações do AMSA (1978) e foram realizadas no Departamento deZootecnia, do Instituto de Zootecnia, em Nova Odessa, SP.

A AS foi realizada no Laboratório de Análises Sensoriais do Departamento de Tecnologia de Alimentos da ESALQ-USP, seguindo-se os procedimentos do AMSA (1978). Foram utilizadas 50 pessoas (provadores) que receberam duas amostras de carne de cada tratamento (totalizando 100 resultados) e fornecida uma ficha de avaliação, que constava de uma escala hedônica de 8 pontos para maciez, suculência, sabor e avaliação geral $(8=$ menos macio, suculento, saboroso; 1 = mais macio, suculento, saboroso). A avaliação estatística dos resultados da análise sensorial foi feita por intermédio do programa SAS (1990), seguindo um modelo estatístico inteiramente casualizado, que envolveu dois tratamentos ( 0 e 630 g de propionato de cálcio) e 50 repetições (provadores).

R. Bras. Zootec., v.32, n.5, p.1213-1219, 2003 
Aplicou-se a técnica de análise de variância para a comparação das médias dos tratamentos, uma vez que as pressuposições para uso da técnica ANOVA foram satisfeitas.

A coleta de amostras de sangue foi feita no dia do abate, quando da exposição da veia jugular do animal. Nessas amostras foi analisada a concentração de cálcio $\left(\mathrm{Ca}_{\mathrm{p}}\right)$, no Laboratório de Análise de Solos da USP-ESALQ, em Piracicaba, utilizando-se da metodologia de absorção atômica.

Utilizou-se um delineamento inteiramente casualizado, envolvendo dois tratamentos $(0$ e $630 \mathrm{~g}$ de propionato de cálcio) e 12 repetições (totalizando 24 animais). Por meio de um esquema de comparações múltiplas, por intermédio do teste Tukey, foi observado o comportamento das variáveis: PV, PCQ, PCR, pH, AOL, EG, GRPI, RQ, RF, PTE, PD, PPA, PGRPI, $\mathrm{AOL} / 100 \mathrm{~kg}$ de carcaça resfriada, EG/100 kg de carcaça, CA na carne e plasma, considerando-se os valores de cada repetição para cada tratamento. Para as variáveis WBSF, PPE, PPG e PPT foi adotado um esquema de parcelas subdivididas, tendo-se para as parcelas as duas doses de propionato de cálcio $(0 \mathrm{e}$ $630 \mathrm{~g})$ e para as subparcelas os três períodos de maturação (1, 8 e 15 dias).

\section{Resultados e Discussão}

\section{Características da carcaça}

Não houve diferenças entre os tratamentos usados $(\mathrm{P}>0,05)$, para as características PV, PCQ, PCR, TE, D5C, PA, AOL, AOL/100 kg carcaça resfriada, EG, EG/100 kg carcaça resfriada, T0, T24, pH24, RF, PTE, PD e PPA (Tabela 1). Estes resultados são similares aos encontrados por Duckett et al. (1998, 2001).

Para o pH0 não houve diferença entre os tratamentos $(\mathrm{P}>0,05)$, sendo que esse resultado diferiu dos encontrados por Duckett et al. (1998, 2001), que observaram menores valores para o tratamento com propionato de cálcio.

Houve diferenças para a PGRPI $(\mathrm{P}<0,05)$, sendo que para o tratamento com propionato de cálcio os valores médios obtidos foram maiores $(9,37 \%)$ que do controle. Este resultado diferiu do encontrado por Duckett et al. (1998), que não encontraram diferenças entre os tratamentos estudados.

Para o RQ, os tratamentos diferiram entre $\operatorname{si}(\mathrm{P}<0,05)$, mostrando menores valores médios $(4,29 \%)$ para o tratamento com propionato de cálcio.

Concentração de cálcio plasmático

A concentração de cálcio plasmático nos animais tratados com propionato de cálcio foi superior $(9,19 \%)$ ao dos animais controle (Tabela 2). Esse resultado se assemelha aos encontrados por Duckett et al. (1999b, 2000, 2001). Desse modo, é demonstrado que a absorção do propionato de cálcio é rápida, o que foi constatado por Duckett et al. (1999b, 2000, 2001) e Sanchez et al. (1995), que encontraram diferenças na concentração de cálcio plasmático entre os tratamentos testados, a partir de 30 minutos após a administração do tratamento, permanecendo essa concentração elevada por mais 6 horas.

Concentração de cálcio muscular

Os valores de cálcio no músculo Longissimus dorsi não diferiram entre os tratamentos estudados $(\mathrm{P}<0,05)$. Os resultados (Tabela 2 ) mostram pequeno aumento na concentração de cálcio $(2,83 \%)$ para os animais tratados com propionato de cálcio. Os resultados diferem aos encontrados por Duckett et al. (1998, 2001), Hanson et al. (2001) e Sanchez et al. (1997), que citam aumentos significativos na concentração de cálcio (de 9 a 25\%). Talvez a razão para a similaridade entre os tratamentos seja devido ao abate dos animais ser realizado 12 horas após a administração do produto, e pelo seu fornecimento ser feito através da diluição em água. Segundo Duckett et al. $(1998,2001)$, fornecendo-se propionato de cálcio, 3 a 6 horas antes do abate, faz com que haja um aumento da difusão passiva de cálcio, do lúmen para os fluídos extracelulares, quando a concentração lumenal é elevada. Segundo Stallings (1998), o propionato de cálcio e o propileno glicol são usados para produzir glicose e reduzir a produção de cetona, então, a combinação entre ambos faz com que sejam usados como um possante produto (“drench") que eleva a concentração de cálcio plasmático. Já de acordo com Goff et al. (1996) e Goff \& Horst (1994), a combinação entre o propionato de cálcio e o propileno glicol não apresenta efeito imediato na elevação do cálcio plasmático, mas apresenta as vantagens de manter o aumento de cálcio no plasma por mais tempo, ser menos irritante da mucosa digestiva e não causar acidose metabólica. Além disso, outros trabalhos acrescentam cálcio ( 75 a $150 \mathrm{~g}$ ) na mistura de propionato de cálcio e propileno glicol (Duckett et al., 1999b; Sanchez et al., 1995).

Força de cisalhamento e Perdas por cozimento

A WBSF não foi afetada pelo fornecimento de propionato de cálcio (Tabela 3 ). Numericamente a diferença da WBSF entre os tratamentos foi de apenas $8,65 \%(\mathrm{P}>0,05)$. Entretanto, houve efeito do

R. Bras. Zootec., v.32, n.5, p.1213-1219, 2003 
Tabela 1 - Valores médios, mínimos e máximos das características de carcaças de bovinos castrados 3/4Simental + $1 / 4$ Nelore tratados com propionato de cálcio

Table 1 - Carcass traits means values of 3/4Simenthal $+1 / 4$ Nellore steers calcium propionato treated

\begin{tabular}{|c|c|c|c|}
\hline $\begin{array}{l}\text { Característica }^{1} \\
\text { Trait }^{1}\end{array}$ & $\begin{array}{l}\text { Média observada } \\
\text { Observed mean }\end{array}$ & $\begin{array}{l}\text { Mínimo } \\
\text { Minimum }\end{array}$ & $\begin{array}{l}\text { Máximo } \\
\text { Maximum }\end{array}$ \\
\hline $\begin{array}{l}\text { Peso vivo }(\mathrm{kg}) \\
\text { Live weight }\end{array}$ & 460,50 & 409,00 & 516,00 \\
\hline $\begin{array}{l}\text { Gordura renal, pélvica, inguinal }(\mathrm{kg}) \\
\text { Inguinal, pelvic and renal fat }\end{array}$ & 6,14 & 4,10 & 11,10 \\
\hline $\begin{array}{l}\text { Porcentagem de gordura renal, pélvica, inguinal (\%) } \\
\text { Inguinal, pelvic and renal fat percentage }\end{array}$ & 1,34 & 0,80 & 2,60 \\
\hline $\begin{array}{l}\text { Peso da carcaça quente }(\mathrm{kg}) \\
\text { Hot carcass weight }\end{array}$ & 250,94 & 223,00 & 280,30 \\
\hline $\begin{array}{l}\text { Rendimento quente (\%) } \\
\text { Hot dressing percentage }\end{array}$ & 54,52 & 50,80 & 59,40 \\
\hline $\begin{array}{l}\text { Peso da carcaça resfriada }(\mathrm{kg}) \\
\text { Chilled carcass weight }\end{array}$ & 247,12 & 220,30 & 274,70 \\
\hline $\begin{array}{l}\text { Rendimento frio }(\%) \\
\text { Chilled dressing percentage }\end{array}$ & 53,84 & 45,00 & 65,10 \\
\hline $\begin{array}{l}\text { Traseiro especial }(\mathrm{kg}) \\
\text { Special hindquarter weight }\end{array}$ & 113,29 & 100,10 & 127,70 \\
\hline $\begin{array}{l}\text { Porcentagem do traseiro especial (\%) } \\
\text { Special hindquarter percentage }\end{array}$ & 45,95 & 38,50 & 56,10 \\
\hline $\begin{array}{l}\text { Dianteiro com } 5 \text { costelas }(\mathrm{kg}) \\
\text { Forequarter weight }\end{array}$ & 90,22 & 78,40 & 101,90 \\
\hline $\begin{array}{l}\text { Porcentagem do dianteiro }(\%) \\
\text { Forequarter percentage }\end{array}$ & 36,60 & 29,80 & 43,30 \\
\hline $\begin{array}{l}\text { Ponta de agulha }(\mathrm{kg}) \\
\text { "Ponta de agulha" weight }\end{array}$ & 38,85 & 33,40 & 43,20 \\
\hline $\begin{array}{l}\text { Porcentagem de ponta de agulha }(\%) \\
\text { "Ponta de agulha" percentage }\end{array}$ & 15,74 & 13,10 & 18,80 \\
\hline $\begin{array}{l}\text { Área do olho do lombo }\left(\mathrm{cm}^{2}\right) \\
\text { Loin eye area }\end{array}$ & 67,79 & 57,00 & 78,00 \\
\hline $\begin{array}{l}\text { AOL } / 100 \mathrm{~kg} \text { carcaça resfriada } \\
L E A / 100 \mathrm{~kg} \text { carcass weight }\end{array}$ & 27,56 & 22,20 & 33,90 \\
\hline $\begin{array}{l}\text { Espessura da gordura }(\mathrm{cm}) \\
\text { Fat thickness }\end{array}$ & 0,50 & 0,20 & 1,00 \\
\hline $\begin{array}{l}\text { EG/100 kg carcaça resfriada } \\
\text { FT/100 kg carcass weight }\end{array}$ & 0,21 & 0,10 & 0,40 \\
\hline $\begin{array}{l}\text { Temperatura } 0 \mathrm{~h}\left({ }^{\circ} \mathrm{C}\right) \\
0 \text { h temperature }\left({ }^{\circ} \mathrm{C}\right)\end{array}$ & 35,12 & 32,40 & 37,30 \\
\hline $\begin{array}{l}\text { Temperatura } 24 \text { hs }\left({ }^{\circ} \mathrm{C}\right) \\
24 \text { hs temperature }\left({ }^{\circ} \mathrm{C}\right)\end{array}$ & 7,33 & 2,60 & 10,70 \\
\hline $\begin{array}{l}\mathrm{pH} 0 \\
\mathrm{pH} 24\end{array}$ & $\begin{array}{l}6,39 \\
5,65\end{array}$ & $\begin{array}{l}5,40 \\
5,40\end{array}$ & $\begin{array}{l}6,70 \\
6,60\end{array}$ \\
\hline
\end{tabular}


Tabela 2 - Valores médios das concentrações de cálcio plasmático e cálcio muscular de bovinos castrados $3 / 4$ Simental $+1 / 4$ Nelore tratados com propionato de cálcio

Table 2 - Average values for plasma and muscular calcium concentration of 3/4 Simenthal + $1 / 4$ Nellore steers calcium propionate treated

\begin{tabular}{|c|c|c|c|}
\hline \multirow[t]{2}{*}{$\begin{array}{l}\text { Característica }^{1} \\
\text { Trait }^{1}\end{array}$} & \multicolumn{2}{|c|}{$\begin{array}{l}\text { Média } \\
\text { Mean }\end{array}$} & \multirow[t]{2}{*}{$\begin{array}{c}\text { Coeficiente de variação }(\%) \\
\text { Coefficient of variation }\end{array}$} \\
\hline & $\begin{array}{l}\text { Controle } \\
\text { Control }\end{array}$ & $\begin{array}{l}\text { Propionato } \\
\text { Propionate }\end{array}$ & \\
\hline $\begin{array}{l}\mathrm{CAp}\left(\mathrm{mL} \mathrm{dL}^{-1}\right) \\
p C A\end{array}$ & $9,79^{\mathrm{b}}$ & $10,69^{\mathrm{a}}$ & 7,43 \\
\hline $\begin{array}{l}\mathrm{CAm}\left(\mathrm{mg} \mathrm{g}^{-1}\right) \\
m C A\end{array}$ & $132,58^{a}$ & $136,33^{a}$ & 13,70 \\
\hline $\begin{array}{ll}1 & C A p=\text { concen } \\
a, b & \text { Médias seguic } \\
1 & p C A=\text { plasmaca } \\
a, b & \text { Means followed }\end{array}$ & $\begin{array}{l}\text { cio plasmá } \\
\text { a letra na } \\
\text { tion, } m C A=\end{array}$ & $\begin{array}{l}=\text { concentra } \\
\text { diferem }(P>0, \\
\text { alcium concentr }\end{array}$ & $\begin{array}{l}\text { cálcio muscular. } \\
\text { nificantemente. }\end{array}$ \\
\hline
\end{tabular}

Tabela 3 - Médias da força de cisalhamento, das perdas por evaporação, das perdas por gotejamento e das perdas totais em relação ao tratamento, tempo de maturação e a interação tratamento $X$ tempo de maturação em carcaças de bovinos castrados $3 / 4$ Simental+1/4Nelore tratados com propionato de cálcio

Table 3 - Means of shear force, evaporation loss, drip loss and total loss by trait, ageing time and treatment versus interaction ageing time of $3 / 4$ Simenthal+1/4 Nellore steers calcium propionate treated

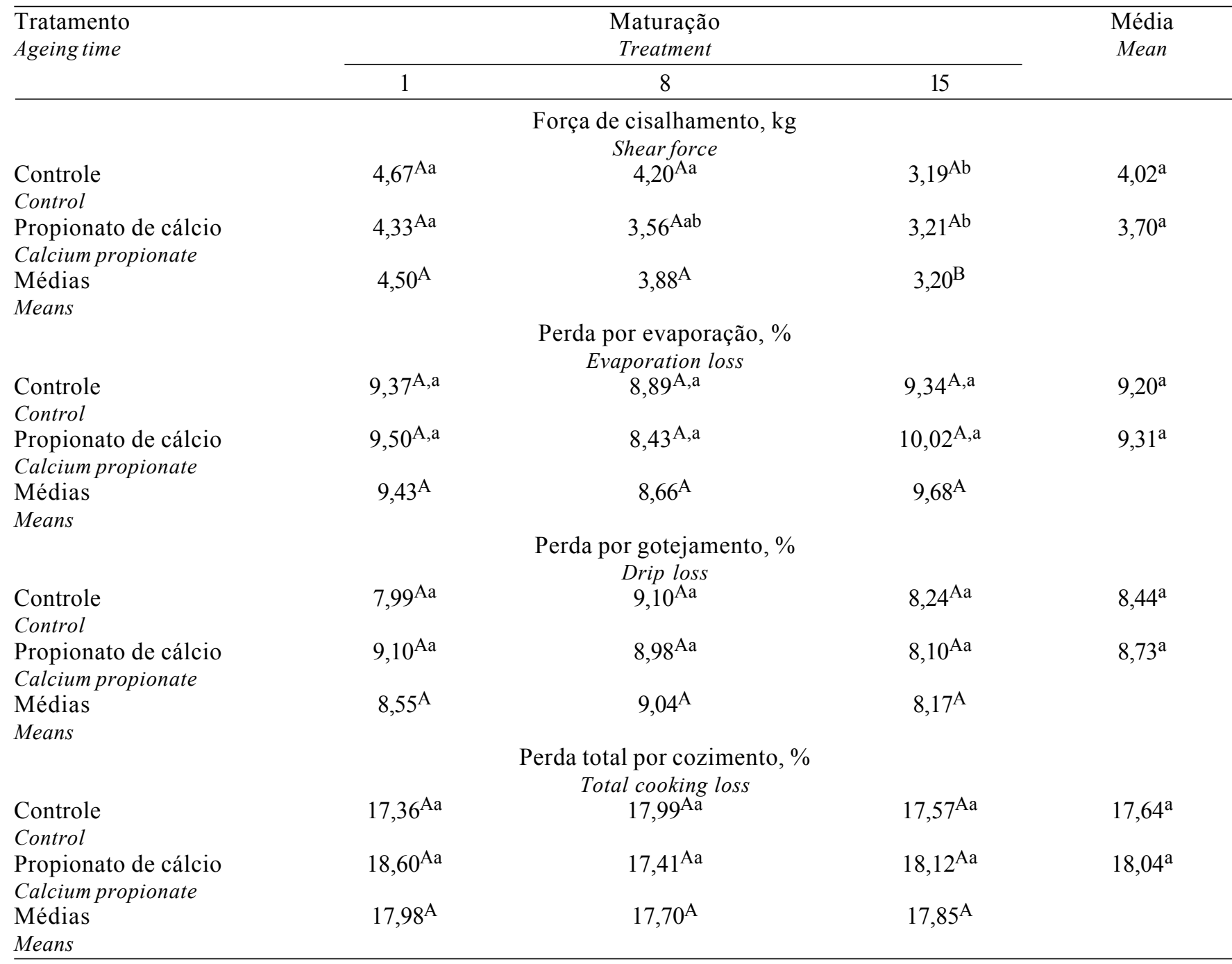

Médias, na linha/coluna, seguidas de letras maiúsculas/minúsculas diferentes são diferentes $(\mathrm{P}<.05)$.

Means, with a row/column, followed by capital/small different letters are different $(P<.05)$. 
Tabela 4 - Valores médios das características sabor, suculência, maciez e análise geral da análise sensorial realizada em carcaças de bovinos castrados 3/4Simental+1/ 4Nelore tratados ou não, com propionato de cálcio

Table 4 - Mean values for sensorial analysis of 3/4 Simenthal+1/4 Nellore steers or not, with calcium propionate treated

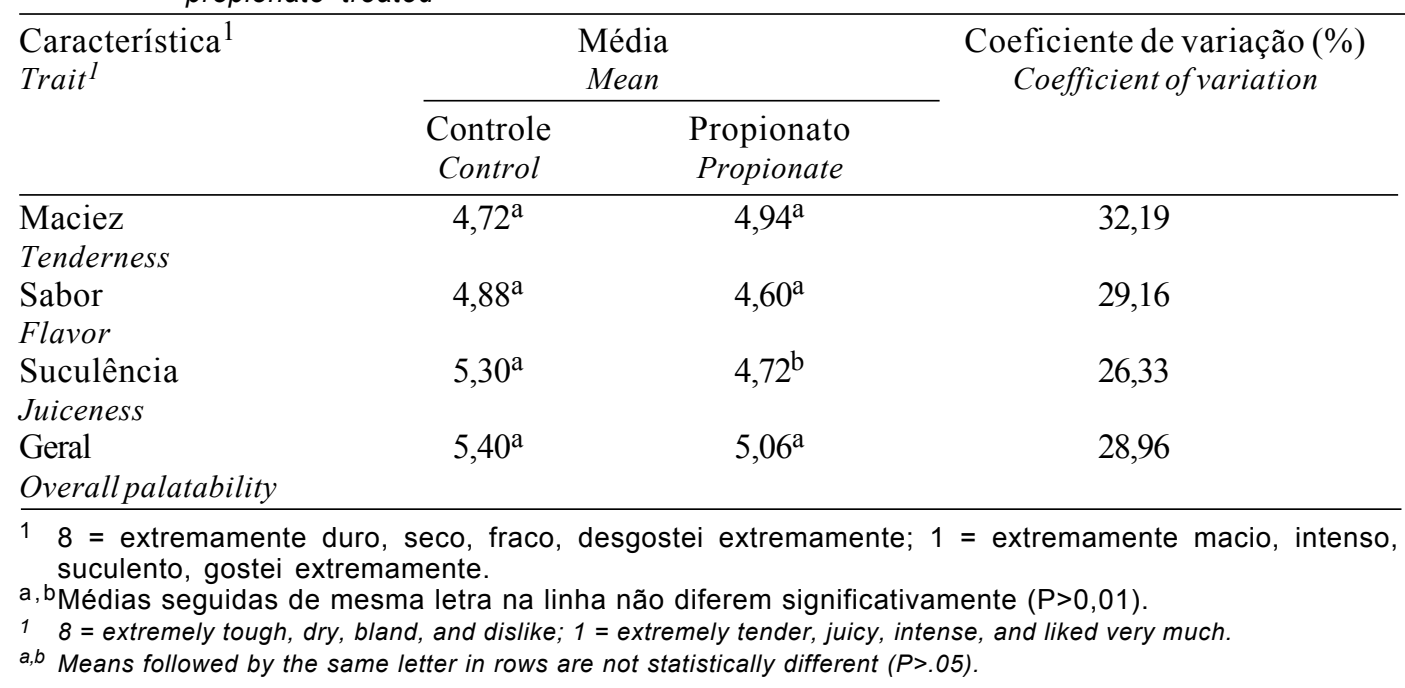

tempo de maturação sobre a WBSF $(\mathrm{P}<0,05)$. Observa-se que, quanto maior o tempo de maturação, menor a WBSF, com menor WBSF para o tempo de maturação de 15 dias $(15,98 \%$ mais macio entre os dias 1 e 8 de maturação, e de $21,25 \%$ mais macio entre os dias 8 e 15 de maturação, totalizando $40 \%$ de maciez entre os dias 1 e 15 de maturação).

Os resultados diferem dos apresentados por Duckett et al. $(1998 ; 2000 ; 2001)$ e Hanson et al. (2001), que observaram redução significativa nos valores de WBSF para carne dos animais tratados com propionato de cálcio; entretanto Duckett et al. (1999a) não encontraram diferenças na maciez de cordeiros "callipyge" tratados com propionato de cálcio.

A explicação para as diferenças de maciez entre os tratamentos, encontrados por outros autores, foi o acréscimo de cálcio $(75 \mathrm{a} 150 \mathrm{~g})$ na mistura de propionato de cálcio e propileno glicol (Sanchez et al., 1995; Duckett et al., 1998, 1999b, 2000, 2001). Quando baixos níveis de cálcio foram adicionados na mistura de propionato de cálcio e propileno glicol (Duckett et al., 1999a), a maciez entre os tratamentos foi igual $(\mathrm{P}>0,05)$, o que demonstra que somente o propionato de cálcio não é suficiente para aumentar a maciez da carne, apesar de aumentar a concentração de cálcio plasmático.

Não foram encontradas diferenças entre os tratamentos e os tempos de maturação estudados $(\mathrm{P}>0,05)$, para as características perdas por evaporação, perdas por gotejamento e perdas totais (Tabela 3).
Análise sensorial

Não foram encontradas diferenças $(\mathrm{P}>0,05)$ na análise sensorial, para as características maciez, sabor e avaliação geral (Tabela 4). Apenas para a característica suculência observou-se que, o tratamento com propionato de cálcio proporcionou carnes mais suculentas $(12,29 \%$ mais suculento). Em trabalho de Duckett et al. (2001), os resultados da análise sensorial mostraram que bifes de animais tratados com propionato de cálcio e maturados por 7 dias tiveram melhor maciez sensorial, valores iguais para suculência e sabor sensorial.

\section{Conclusões}

O tratamento com propionato de cálcio não tem efeito sobre as características de carcaça, com diferença apenas para os valores de PGRPI e o RQ.

A concentração de cálcio plasmático nos animais tratados com propionato de cálcio é superior ao dos animais controle.

Os valores de cálcio no músculo Longissimus dorsi não diferem entre os tratamentos estudados.

A força de cisalhamento, a maciez, o sabor e as perdas por cozimento não são afetadas pelo fornecimento de propionato de cálcio, mas a suculência aumenta com o tratamento com propionato de cálcio.

Novos experimentos devem ser realizados, para se estudar a vantagem da adição de cálcio e o nível de 
cálcio na mistura de gel de propionato de cálcio, o melhor momento para a administração de propionato de cálcio no sistema de abate brasileiro, e adição de substâncias para melhorar a eficiência da mistura de gel, visando melhorar a maciez e a conservação da carne destinada ao consumo.

\section{Literatura Citada}

AMERICAN MEAT SCIENCE ASSOCIATION - AMSA. Guidelines for cookery and sensory evaluation of meat. Illinois: National Livestock and Meat Board, 1978. 24p.

DUCKETT, S.K.; KLEIN, T.A.; ANDRAE, J.G.; SANCHEZ, W.K. Pre-harvest tenderization through oral calcium gel administration. Journal of Animal Science, v.76, Suppl.1, p.156, 1998.

DUCKETT, S.K.; ANDRAE, J.G.; PRITCHARD, G.T. et al. Pre- and post-harvest tenderization of callipyge lamb. Journal of Animal Science, v.77, Suppl.1, p.170, 1999a.

DUCKETT, S.K.; ANDRAE, J.G.; PRITCHARD, G.T. et al. Effects of oral calcium gel propionate dose level on serum calcium levels of feedlot steers. Journal of Animal Science, v.77, Suppl.1, p.241, 1999 b.

DUCKETT, S.K.; ANDRAE, J.G.; PRITCHARD, G.T. et al. Effect of pre-harvest oral calcium gel administration on tenderness. Journal of Animal Science, v.78, Suppl.1, p.155, 2000.

DUCKETT, S.K; ANDRAE, J.G.; PRITCHARD, G.T. et al. Effects of pre-slaughter administration of oral calcium gel to beef cattle on tenderness. Canadian Journal of Animal Science, v.81, n.1, p.33-38, 2001.

GOFF, J.P.; HORST, R.L. Calcium salts for treating hypocalcemia: carrier effects, acid-base balance, and oral versus rectal administration. Journal of Dairy Science, v.77, n.5, p.1451-1456, 1994.

GOFF, J.P.; HORST, R.L.; JARDON, P.W. et al. Field trials of an oral calcium propionate paste as an aid to prevent milk fever in periparturient dairy cows. Journal of Dairy Science, v.79, n.3, p.378-383, 1996.

GOLL, D.E. Role of protinases and protein turnover in muscle growth and meat quality. Proceedings of Reciprocal Meat Conference, v.44, p.25-33, 1991.
HANSON, D.J.; CALKINS, C.R.; HORTON, J.M. The effects of calcium loading on tenderness of beef Longissimus, Supraspinatus and Semitendinosus muscles. Journal of Animal Science, v.79, Suppl.1, p.64-65, 2001.

MOURA, A.C.; LUCHIARI FILHO, A.; LANDAETA, F. A.C.; ZINSLY, C.F. Estudo da utilização de cloreto de cálcio no amaciamento da carne de coelho através do processo de marinação. In: REUNIÃO ANUAL DA SOCIEDADE BRASILEIRA DE ZOOTECNIA, 33., 1996, Fortaleza. Anais... Fortaleza: Sociedade Brasileira de Zootecnia, 1996. v.1, p.579-581.

MOURA, A.C.; LUCHIARI FILHO, A.; NARDON, R.F. et al. Efeito da injeção pós-morte de cloreto de cálcio e tempo de maturação, no amaciamento e perdas por cozimento do músculo Longissiumus dorsi de animais Bos indicus e Bos taurus selecionados para ganho de peso. Revista Brasileira de Zootecnia, v.28, n.6, p.1382-1389, 1999.

SANCHEZ, W.K.; HIGGINS, J.J.; GUY, M.A. et al. Effect of an oral calcium propionate gel on calcium and acid-base status of dairy cows. Journal of Dairy Science, v.78, Suppl.1, p. $185,1995$.

SAS STATISTICAL SYSTEM. User's guide: Stat. Version 6, 4.ed. Cary: 1990. v.2.

SCANGA, J.A.; BELK, K.E.; TATUM, J.D. et al. Supranutritional oral supplementation with vitamin $\mathrm{D}_{3}$ and calcium and the effects on beef tenderness. Journal of Animal Science, v.79, n.4, p.912-918, 2001.

STALLINGS, C.C. Feeding management during the transition phase. 6p. 1998. http://www.afns.ualberta.ca/ hosted/wcds/wcd98/ch03.htm (18/02/2002)

SWANEK, S.S.; MORGAN, J.B.; OWENS, F.N. et al. Vitamin $\mathrm{D}_{3}$ supplementation of beef steers increases longissimus tenderness. Journal of Animal Science, v.77, n.4, p.874-881, 1999.

Recebido em: 05/07/02 Aceito em: 26/11/02 